Research Article

\title{
Investigation on the Properties and Distribution of Air Voids in Porous Asphalt with Relevance to the Pb(II) Removal Performance
}

\author{
Yao Zhao ${ }^{D}{ }^{1}{ }^{1}$ Lei Tong, ${ }^{2}$ and Yating $\mathrm{Zhu}^{1}$ \\ ${ }^{1}$ College of Civil Engineering, Nanjing Forestry University, 159 Longpan Road, Nanjing 210037, China \\ ${ }^{2}$ Jiangsu Sinoroad Engineering and Technology Institute Ltd., Co., 14th Floor of Kechuang Square, 88 Pubin Road, \\ Nanjing 210016, China \\ Correspondence should be addressed to Yao Zhao; zhaoyaonfu@163.com
}

Received 11 April 2019; Revised 7 June 2019; Accepted 25 June 2019; Published 11 July 2019

Academic Editor: Francesco Ruffino

Copyright (C) 2019 Yao Zhao et al. This is an open access article distributed under the Creative Commons Attribution License, which permits unrestricted use, distribution, and reproduction in any medium, provided the original work is properly cited.

In this study, one type of porous asphalt (PA) mixture was designed at two different air void (AV) contents. Direct information regarding both the dimensional properties and AV distribution within two PA specimens in their natural states were observed, compared, and analyzed based on the X-ray CT (computed tomography) and digital image analysis techniques and fractal geometry theory. The characteristics of AV distribution, including AV content, AV number, and AV volume were quantified by comparing pore structure at different specimen heights. The dimensional properties of voids at different specimen heights were characterized by parameters in terms of equivalent diameter, specific surface area, and fractal dimension. The $\mathrm{Pb}(\mathrm{II}) \mathrm{removal}$ performance of the two PA mixtures was examined by an artificial rainfall event. The relationship between the PA microstructure and $\mathrm{Pb}(\mathrm{II})$ removal rate was then determined. It is observed from this study that the overall distribution pattern of $\mathrm{AV}$ inside $\mathrm{PA}$ specimen is independent of AV content. The distributional parameters including AV content, AV number, and AV volume show good correlations with three dimensional parameters, respectively. The $\mathrm{Pb}$ (II) removal in general appears to be independent of $\mathrm{AV}$ content because both $\mathrm{PA}$ mixtures have the same level of performance in removing $\mathrm{Pb}$ (II) during the rainfall period. The removal rate of $\mathrm{Pb}(\mathrm{II})$ shows good correlation with $\mathrm{AV}$ content, $\mathrm{AV}$ number, $\mathrm{AV}$ volume, and equivalent diameter of $\mathrm{AV}$, indicating that a perfect distribution of AV within PA mixture is more important than the complex geometries of voids for getting a higher $\mathrm{Pb}$ (II) removal during rainfall event and without providing a temporary storage of stormwater in PA mixture. These findings provide an effective evidence to reveal that the AV distribution and properties characteristics have significant implications for pollutant removal in field PA pavement system.

\section{Introduction}

Porous asphalt (PA) pavement systems, a group of typical permeable pavement systems (PPS), are recommended as an effective infrastructure for current low-impact development (LID) and sustainable urban stormwater management $[1,2]$. Generally, a standard PA pavement system consists of three main layers including PA surface, choker course and reservoir structure with various porous materials from top to bottom [3-5]. As a result, a complex network of interconnected air voids is formed within it. These air void spaces make the system work as a filtration media. Rainwater that falls on the pavement surface can freely penetrate through the pavement structure into subsoil during wet weather.
Meanwhile, physical and chemical processes are taking place. Thus, a PA system can effectively reduce stormwater runoff volumes, delay and decrease peak flows, support groundwater recharges and improve stormwater runoff quality on site [6-8].

PA mixture, also known as new generation open-graded friction course (OGFC) mixture or permeable friction course (PFC) mixture, is a type of hot mixture asphalt (HMA) with high coarse aggregate content and low fine aggregate content when compared to conventional densegraded HMA that leads to a higher total AV content of 18 25\% [9-11]. The AVs contained in PA mixtures make it an ideal surface layer material for the innovative full-depth PA pavement system. The proper functionality in terms of 
peak flow reduction, surface infiltration capacity, and stormwater treatment can be ensured. Therefore, PA mixtures are currently attracting more and more attention in both pavement engineering and stormwater management [12].

Previous studies have assessed the stormwater quality and hydraulic performance of PA surface/system in terms of metallic pollutant removal capability and surface infiltration capacity [13-18]. Stotz and Krauth [13] and Eck et al. [14] found that the total $\mathrm{Pb}$ concentration in the runoff from highway with the PA surface was 56 96\% lower than that discharging from traditional highway with the impermeable surface. Zhao and Zhao [18] evaluated the $\mathrm{Pb}$ removal performance of a PA system providing temporary storage for stormwater, and the results showed that $90 \%$ of total $\mathrm{Pb}$ was removed from initial flush. Legret et al. [4] confirmed that most $\mathrm{Pb}$ from stormwater was trapped in the voids of the PA surface but not in the soil directly under the PA structure. Roseen et al. [16] and Al-Rubaei et al. [17] examined the surface infiltration of a PA system in a cold-weather climate. Observations showed that PA in New Hampshire still worked well with a satisfactory surface permeability of over $0.14 \mathrm{~cm} / \mathrm{s}$ when the maximum frost penetration depth was nearly $71 \mathrm{~cm} \mathrm{[16]} \mathrm{and} \mathrm{the} \mathrm{PA} \mathrm{in} \mathrm{northern} \mathrm{Sweden} \mathrm{had} \mathrm{a}$ reduction in infiltration capacity due to pavement age and clogging but could still infiltrate an intense design rainfall (100-year average return interval, 15 min duration) [17]. Chen et al. [15] revealed that the permeability of PA mixture was not only affected by rainfall intensity and transverse cross slope, but also the internal AV structure. Other related researches also ascribed these excellent functional advantages to the microstructure of the PA mixture [10, 19-22]. As demonstrated by these studies, PA surface is effective in improving runoff water quality by treating and trapping metallic pollutants, such as $\mathrm{Pb}$, in addition to reducing surface runoff and flow peaks; but the level of hydraulic performance and pollutants removal capability is not quantitatively consistent. It is affected by pavement type, geographic location, climate condition, pavement age, maintenance, and the species of stormwater pollutant in addition to the AV characteristics. The AV characteristics of those are indicated as an important consideration in PA mixture design, construction, and assessment. Unfortunately, little research has provided further insight into the PA mixture microstructure in terms of the dimensional properties and distribution of AV and its relation to metallic pollutant removal.

Based on Darcy's law, the hydraulic conductivity of PA mixture and certain impacts caused by the total AV content or aggregate gradation can be measured by setting up appropriate laboratory devices [23-27]. Apparently, traditional techniques are not adequate to accurately quantify and describe the content, number, size, shape, and distribution of $\mathrm{AV}$ in a PA mixture. With the development of X-ray CT and digital image analysis technologies, investigation on the internal structure of PA mixture on a microscopic level was made possible. Since then, research focused on studying the specific AV characteristics in PA mixture and its contribution to the functional properties has been increased.
In the early study by Alvarez et al. [10], the dimensional analysis with application of a laboratory method of using vacuum water and X-ray $\mathrm{CT}$ and image analysis with inclusion of surface AV were recommended for determining water-accessible AV content and interconnected AV content, respectively. In 2010, Alvarez et al. [20] comparably analyzed the internal structure of two PA mixtures and assessed in terms of AV characteristics based on X-ray CT and image analysis techniques. Results showed that the horizontal AV distributions of both mixtures were heterogeneous, but limitations still existed to compare the vertical AV distributions. Furthermore, Alvarez et al. [28] characterized the stone-on-stone contact conditions of PA mixture fabricated with two types of asphalt binder based on the digital image analysis. Their findings supported the importance of verifying both the Cantabro loss and voids in the coarse aggregate ratio in properly screening the PA mixture performance. They also indicated that controlling the compaction process helps to fully develop the stone-onstone contact condition. Hassan et al. [11] indicated that AV characteristics including the total AV content, AV number, and AV size (area) in vertical and horizontal sections were able to describe the influence of AV formation with the mixture on the permeability rate of PA. Mahmud et al. [29] observed most of the AVs in PA mixtures were elongated, and the percentage of AV and number of AV in the crosssectional images of the PA mixture had an inverse relationship. Overall, pioneering research has confirmed that $\mathrm{X}$-ray CT and related image analysis techniques are the effective and practical tools helping to characterize the properties and distribution of AV in PA mixtures on the microscale. Findings also support the currently available parameters and methods for PA mixture design and construction while indicating the positive relationship between the AV characteristics and the hydraulic performance of PA mixtures. However, a very limited number of studies have been conducted to explore the influence of the specific AV characteristics in $\mathrm{PA}$ mixtures on stormwater pollutant removal. Furthermore, no research has compared the stormwater quality performance of PA mixtures with different total (or effective) AV contents and investigated the relationship between the specific AV characteristics and the metallic pollutant removal capability.

Stormwater pollution is a worldwide problem that hides modern city development, especially in urbanized country like China. Many cities in China are facing increasing pressure to improve urban stormwater quality management with the rapid pace of urbanization and global climate change. The Chinese government has launched "Sponge City" construction projects to promote innovation and technological advancement in urban stormwater management. Research is imperatively conducted to evaluate the removal of heavy metals from stormwater by PA mixture under different Chinese climate regions and especially for the subtropical monsoon climate in the Southeast, which is one of the most developed and highly populated areas of China. The performance of PA mixture is indicated not only depending on the environmental condition, but also relating to its porous structure. As AV 
characteristics are known to influence the permeability rate of PA mixture, it may affect the pollutant removal capability too. Investigation into the relation between the microstructure of PA mixture and metallic pollutant removal is consequently required.

In this paper, the main objective is to provide detailed information investigation on the microstructure properties and distribution of $\mathrm{AV}$ throughout the PA mixture specimen height and understand the relationship between AV characteristics in certain $\mathrm{PA}$ mixture and the $\mathrm{Pb}$ (II) removal performance under the climate conditions of Nanjing City. In this study, the research was conducted in three phases: (1) characterize and quantify the AV structure in two PA specimens at various $\mathrm{AV}$ contents, using both the dimensional parameters and distributional parameters; (2) investigate the $\mathrm{Pb}(\mathrm{II})$ removal behavior of the same two $\mathrm{PA}$ samples used in the first phase; and (3) determine the relations between $\mathrm{AV}$ characteristics parameters and $\mathrm{Pb}(\mathrm{II})$ removal efficiency. Based on the X-ray CT and digital image analysis techniques, the properties and distribution of $\mathrm{AV}$ in PA mixtures are analyzed using vertical cross-sectional $\mathrm{X}$-ray CT images with dimensional parameters in terms of (1) total AV content, (2) AV number, and (3) AV volume, and distributional parameters in terms of (1) equivalent diameter, (2) specific surface area, and (3) fractal dimension, respectively. The $\mathrm{Pb}(\mathrm{II})$ removal performance of $\mathrm{PA}$ specimens is evaluated by conducting a synthetic rainfall event in the laboratory.

\section{Materials and Methods}

2.1. PA Mixture Design and Material Selection. To investigate the AV structure, one type of PA mixture, PAC-16, was designed at two target AV contents in accordance with the current Chinese Standard of CJJ/T 190-2012 [30]. As shown in Figure 1, PAC-16(A) was prepared at the AV content of approximately $20 \%$, while PAC-16(B) was prepared at the AV content of $16 \%$, used as control. The constituent materials of the PA mixture used in this study are as follows: SBS high-viscosity modified asphalt binder offered by Jiangsu Baoli Asphalt Co., Ltd., crushed basalt aggregates and limestone powder supplied by an aggregate processing plant in Jiangxi Province, and a type of flocculated lignin fibre obtained by Changzhou Perfect Global Project Material Co., Ltd. The properties of all these materials are shown in Table 1. It can be seen from the table that all materials met the Technical Specification of JTG F40-2004 and Technical Specification of CJJ/T 190-2012 [30, 31]. Asphalt binder contents of $5.3 \%$ and $5.0 \%$ by the mixture total weight were used for preparing specimens with $16 \%$ and $20 \%$ of designed AV contents, respectively.

2.2. Specimen Preparation. The PA mixture specimens were compacted using a Marshall Hammer with 50 blows per side, and mixed and compacted at $175^{\circ} \mathrm{C}$ and $170^{\circ} \mathrm{C}$, respectively, according to the Chinese Standard Method of T0702 [32]. Each specimen was prepared with a diameter of $101.6 \mathrm{~mm}$ and height of $63.5 \pm 1.3 \mathrm{~mm}$.
2.3. Laboratory Testing for Basic Properties. The basic physical properties in terms of bulk specific gravity, theoretical maximum specific gravity, measured total AV content, and effective AV content including permeable and dead-end voids of each compacted PA specimen were determined in accordance with specifications of CJJ/T 1902012 [30], JTG F40-2004 [31], and JTG E20-2011 [32]. The properties of the PA samples are provided in Table 2. It can be seen that the measured total AV contents of the two PA specimens are nearly $21 \%$ and $16 \%$, respectively, which is as expected.

2.4. X-Ray CT Analyses and Digital Image Processing. The PA specimens were scanned using a high-resolution industrial $\mathrm{X}$-ray CT Inspection System (YXLON PrecisionII) at Tongji University. This inspection system can scan a specimen with a maximum size of $600 \mathrm{~mm} \times 1250 \mathrm{~mm}$ (diameter $\times$ height) and offer a minimum voxel size of 950 nanometers. In this work, each specimen was detected with a scanning current of $0.35 \mathrm{~mA}$, a scanning voltage of $210 \mathrm{kV}$ and a pixel dimension of $2048 \times 2048$. Computerized two-dimensional (2D) images, representing successive scanned planes perpendicular to the vertical axis of the PA specimen, with a gap of $0.1 \mathrm{~mm}$, were obtained. As these images cannot be directly used for accurate characterization and quantitative analysis, image processing and thresholding are thus required. These procedures were performed by the image analysis software VG Studio $\operatorname{Max}^{\circledR}$ 2.2.2 that converted the original grayscale images to binary images, where black was assigned to the AVs while white represented the aggregates with asphalt mortar (an example is shown in Figure 2). Specifically, each of grayscale images was firstly imported to the VG Studio $\operatorname{Max}^{\circledR}$ 2.2.2, and the region of interest (ROI) was then created. To ensure a constant condition for further analysis, the self-adaptive method (automatic method) was used to process the surface determination, so that the boundaries between the AVs and the aggregates with asphalt mortar were identified from the image. For further quantification of parameters proposed to characterize the microstructure of PA specimen, defect analysis was undertaken through the threshold adjustment on each image.

2.5. Determination of Parameters from Binary Images. To provide detailed information about the AV characteristics within the PA specimen, further calculation and analysis were conducted through these binary images (as the example shown in Figure 2(b)) obtained after applying the threshold value. The AV distribution was analyzed using distributional parameters in terms of AV content, AV number, and AV volume. The shape, inner-surface texture, and the void filling ability were characterized using dimensional parameters in terms of equivalent diameter, specific surface area, and fractal dimension. All parameters besides fractal dimension were computed by using the VG Studio Max ${ }^{\circledR}$ 2.2.2 software. The fractal dimension was calculated using the spatial boxcounting method (according to Alber et al. [33]) by running a MATLAB $^{\circledR}$ program. 


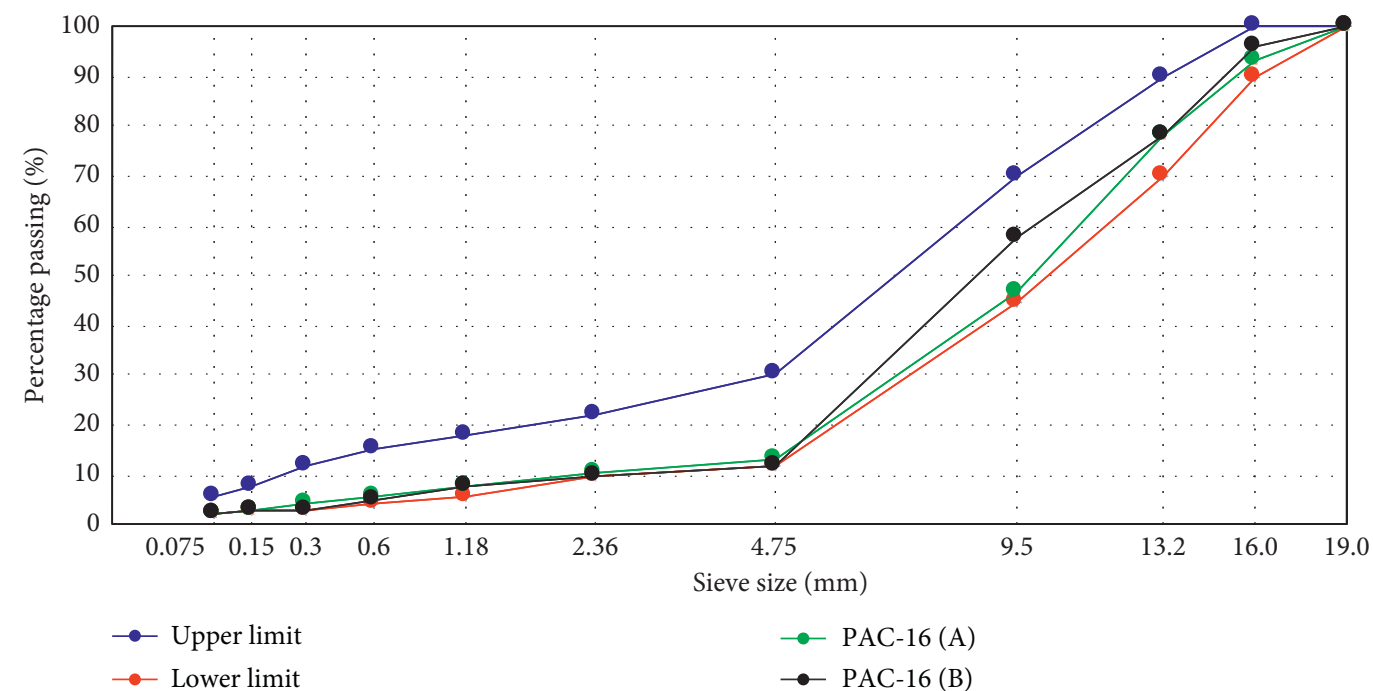

Figure 1: Aggregate gradations at two designed AV contents used for preparing PA specimens.

TABLE 1: Main properties of asphalt, aggregate, filler, and fibre.

\begin{tabular}{|c|c|c|c|c|}
\hline Material & $\begin{array}{c}\text { Physical } \\
\text { properties }\end{array}$ & Unit & $\begin{array}{c}\text { Standard } \\
\text { limit }^{*}\end{array}$ & Result \\
\hline \multirow{6}{*}{ Asphalt binder } & Penetration at $25^{\circ} \mathrm{C}$ & $0.1 \mathrm{~mm}$ & $\geq 40$ & 5.20 \\
\hline & Softening point & ${ }^{\circ} \mathrm{C}$ & $\geq 80$ & 84.00 \\
\hline & Ductility at $15^{\circ} \mathrm{C} / 5^{\circ} \mathrm{C}$ & $\mathrm{cm}$ & $\geq 80$ & $86 / 42$ \\
\hline & Kinematic viscosity at $60^{\circ} \mathrm{C}$ & $\mathrm{Pa} \cdot \mathrm{s}$ & $\geq 20,000$ & 262,000 \\
\hline & Flash point & ${ }^{\circ} \mathrm{C}$ & $\geq 260$ & 290.00 \\
\hline & Loss on heating TFOT & $\%$ & $\leq 0.6$ & 0.12 \\
\hline \multirow{4}{*}{ Coarse aggregate (larger than $2.36 \mathrm{~mm}$ ) } & Crushed value & $\%$ & $\leq 26$ & 15.60 \\
\hline & Los Angeles abrasion value & $\%$ & $\leq 28$ & 13.34 \\
\hline & Apparent specific gravity & - & $\geq 2.6$ & 2.80 \\
\hline & Water adsorption & $\%$ & $\leq 2$ & 0.96 \\
\hline \multirow{4}{*}{ Fine aggregate (smaller than $2.36 \mathrm{~mm}$ ) } & Apparent specific gravity & - & $\geq 2.50$ & 2.72 \\
\hline & Soundness (larger than $0.3 \mathrm{~mm}$ ) & $\%$ & $\geq 10$ & 13.00 \\
\hline & Soil content (smaller than $0.075 \mathrm{~mm}$ ) & $\%$ & $\leq 1$ & 0.84 \\
\hline & Sand equivalent & $\%$ & $\geq 60$ & 65.00 \\
\hline \multirow{2}{*}{ Lime powder } & Apparent gravity & $\mathrm{g} / \mathrm{cm}^{3}$ & $\geq 2.50$ & 2.72 \\
\hline & Water content & $\%$ & $\leq 1$ & 0.20 \\
\hline \multirow{5}{*}{ Fibre } & Fibre cut length & $\mathrm{mm}$ & $\ngtr \mathrm{m}$ & 3.50 \\
\hline & Color & - & - & Gray \\
\hline & Oil adsorption & $\%$ & $\geq 5.0 \%$ by the fibre total weight & 8.60 \\
\hline & Moisture & $\%$ & $\ngtr 5.0$ & 0.00 \\
\hline & $\mathrm{pH}$ value & - & $7.5 \pm 1.0$ & 7.40 \\
\hline
\end{tabular}

*Technical Specification of JTG F40-2004 and Technical Specification of CJJ/T 190-2012.

TABLE 2: Basic properties of the two PA specimens.

\begin{tabular}{lccccc}
\hline Specimen & Specimen height $(\mathrm{mm})$ & $\begin{array}{c}\text { Bulk specific } \\
\text { gravity }\end{array}$ & $\begin{array}{c}\text { Theoretical maximum } \\
\text { specific gravity }\end{array}$ & $\begin{array}{c}\text { Measured total AV content in } \\
\text { specimen (\%) }\end{array}$ & $\begin{array}{c}\text { Effective AV content in } \\
\text { specimen (\%) }\end{array}$ \\
\hline PAC-16(A) & 64.1 & 2.090 & 2.645 & 20.98 & 13.10 \\
PAC-16(B) & 63.8 & 2.217 & 2.634 & 15.83 & 9.12 \\
\hline
\end{tabular}

However, in this study, the primary concern was that the $\mathrm{AV}$ in the PA specimen might be difficult to describe with these $2 \mathrm{D}$ images since $\mathrm{AV}$ is actually one of the volumetric properties for PA mixture. To solve this issue, the differences between two adjacent images were firstly analyzed by conducting a $T$-test, and the results showed no significant 


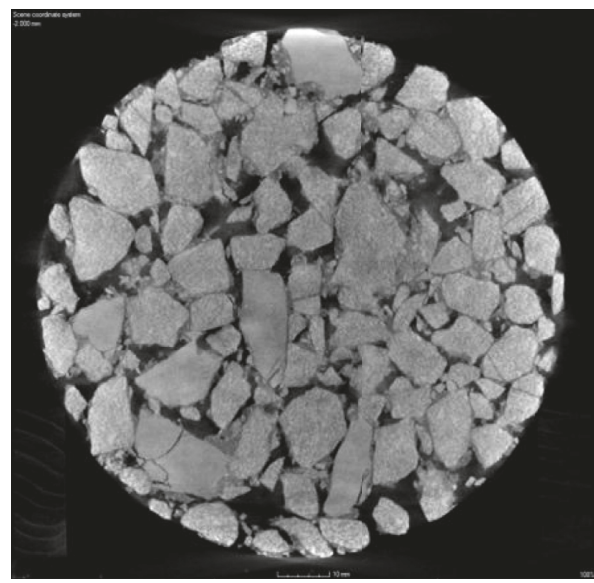

(a)

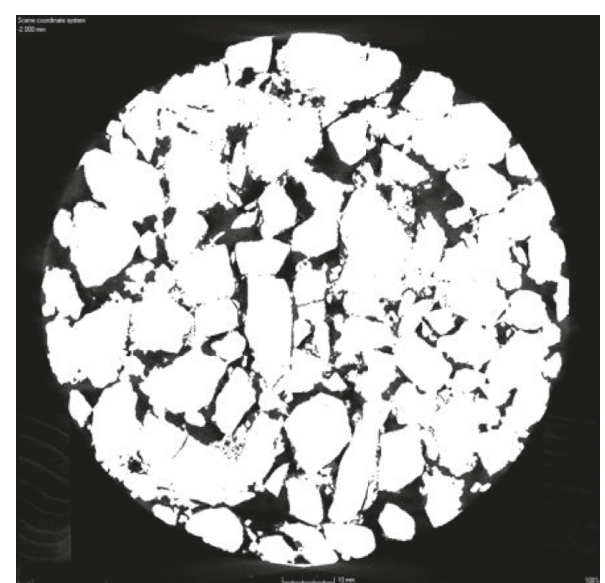

(b)

Figure 2: An example for X-ray CT image analysis using VG Studio Max ${ }^{\circledR} 2.2 .2$ software: (a) original grayscale image; (b) binary image.

difference in the location, size (area), and boundary curve of voids between two adjacent images with a gap of $0.1 \mathrm{~mm}$ $(p>0.05)$. To simplify calculation and analysis, it was then assumed that there is no change in the AV characteristics between two adjacent images, as shown in Figure 3. Based on this assumption, a total of 36 images throughout the sample height, taken at equal intervals of $1.75 \mathrm{~mm}$, were chosen for further analysis, for each PA specimen. Meanwhile, parameters related to the void volume including AV content, $\mathrm{AV}$ volume, equivalent diameter, and specific surface area were analyzed in a specimen slice with a thickness of $0.1 \mathrm{~mm}$. AV number and fractal dimension were directly calculated through the processed images.

Herein, AV content was expressed as the percentage of void spaces within a certain PA specimen slice of thickness $0.1 \mathrm{~mm}$ to the total AV spaces of specimen $S$. It was calculated by equation (1) using VG Studio $\operatorname{Max}^{\circledR}$ 2.2.2 software:

$$
\mathrm{AV}_{s(i)}=\frac{V_{s(i)}}{V_{s}},
$$

where $\mathrm{AV}_{s(i)}$ represented the percent of $\mathrm{AV}$ volume in the PA specimen slice $s(i)$ of specimen $S$ to the total AV volume of specimen $S(\%) ; V_{s(i)}$ was the AV volume in specimen slice $s(i)$ of specimen $S\left(\mathrm{~mm}^{3}\right)$; and $V_{s}$ was the total AV volume of specimen $S\left(\mathrm{~mm}^{3}\right)$.

The AV number was defined as the number of voids within a certain vertical cross-sectional area (circle area) of image $i$. The AV size was defined as the volume of voids of a PA specimen slice $s(i)$. Both were obtained directly by using VG Studio Max $^{\circledR}$ 2.2.2 software.

The parameter equivalent diameter used in this study was the volume equivalent diameter, defined as the diameter of a sphere with the same volume as the average AV in a certain PA specimen slice with a height of $0.1 \mathrm{~mm}$. It was calculated by equation (2) using the VG Studio $\mathrm{Max}^{\circledR}$ 2.2.2 software:

$$
D_{s(i)}=\left(\frac{6 V_{s(i)}}{n(i) \cdot \pi}\right)^{1 / 3},
$$

where $D_{s(i)}$ was the volume-equivalent sphere diameter of the average air void in specimen slice $s(i)(\mathrm{mm})$, and $n(i)$ was the number of voids on cross-section image $i$.

Moreover, the specific surface area was defined as the interstitial surface area of AV per unit bulk volume of specimen slice $s(i)$. It was calculated by the following equation:

$$
S_{s(i)}=\frac{A_{s(i)}}{V_{s}}
$$

where $S_{s(i)}$ was the specific surface area of the voids per unit bulk volume of a PA specimen slice $s(i)\left(\mathrm{mm}^{-1}\right), A_{s(i)}$ was the interstitial surface area of AV in specimen slice $s(i)\left(\mathrm{mm}^{2}\right)$, and $V_{s}$ was the volume of each PA specimen slice $\left(\mathrm{mm}^{3}\right)$, $V_{s}=810.73 \mathrm{~mm}^{3}$.

Fractal geometry theory first proposed by Mandelbort in 1973 has been recommended as a simple and effective tool for characterizing the rough curves of aggregates in asphalt mixture and rough surface of asphalt pavement [34, 35]. Herein, the fractal dimension $D_{i}$ was used to illustrate the complexity, texture, and filling capacity of AV in the PA specimen with the Box-counting method, one of the basic techniques to measure fractal curves $[33,34]$. The fractal dimension was calculated by the following equation [35]:

$$
D_{i}=\lim _{\varepsilon \longrightarrow 0}\left\{\frac{\log \left(N\left(\varepsilon_{i}\right)\right)}{\log \left(1 / \varepsilon_{i}\right)}\right\},
$$

where $N\left(\varepsilon_{i}\right)$ is the number of boxes and $\varepsilon_{i}$ is the box size required to fill the entire area of the voids in image $i(\mathrm{~mm})$.

2.6. Artificial Rainfall Experiment. The specimens tested for laboratory $\mathrm{Pb}(\mathrm{II})$ removal performance were the same samples used for X-ray CT scanning. The artificial rainfall experiment was conducted using synthetic rainwater. The methods and procedures for preparing synthetic rainwater and designing artificial rainfall event can be found in Zhao and Zhao [18] and Zhao et al. [5, 36]. The synthetic rainwater, with an initial $\mathrm{Pb}^{2+}$ concentration of $0.50 \mathrm{mg} / \mathrm{L}$, and the artificial rainfall event with a duration of 120 minutes, 


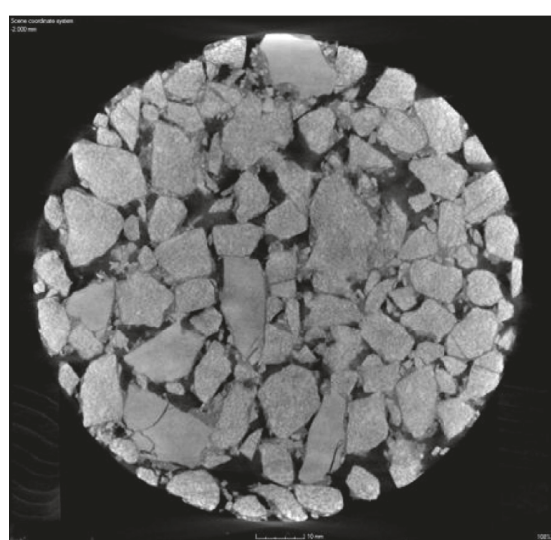

(a)

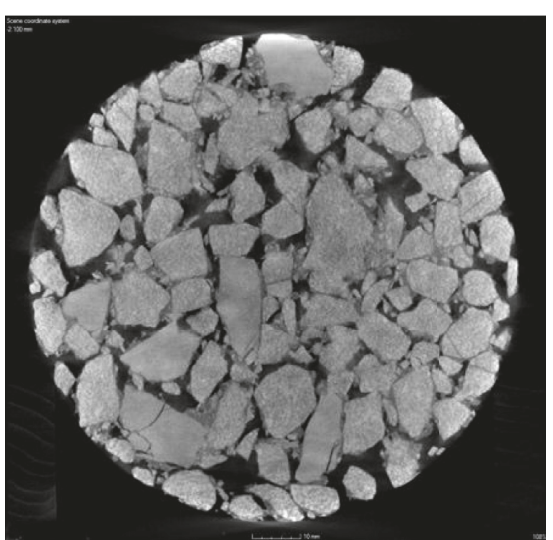

(b)

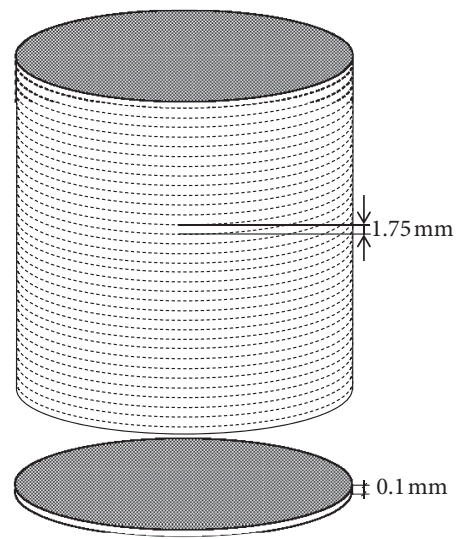

(c)

Figure 3: The assumption for this study: (a) X-ray CT image of PAC-16(A) specimen at $2.0 \mathrm{~mm}$ height, (b) X-ray CT image of PAC-16(A) specimen at $2.1 \mathrm{~mm}$ height, and (c) schematic diagram.

time step of 5 minutes, return period of 5 years, and peak factor $(\gamma)$ of 0.40 , are, respectively, shown in Table 3 and Figure 4.

Following the preparation of synthetic rainwater, the solution was analyzed to measure the initial concentration of $\mathrm{Pb}$ (II). A total of $0.67 \mathrm{~L}$ of synthetic rainwater was then applied to each PA sample by using a lab-made rainfall system shown in the study of Zhao et al. [36]. The scheme of the experiment was shown in Figure 5. Timing commenced once the artificial rainfall began. Effluent samples were collected from the bottom of the PA specimens every 5 minutes until the end of the rainfall event.

Once collected, the samples were acidified by nitric acid, stored in fridge at $4^{\circ} \mathrm{C}$ and then analyzed for $\mathrm{Pb}$ (II) concentrations in accordance with the method of Inductively Coupled Plasma Atomic Emission Spectrometric (ICP-AES) and Microwave Digestion Method.

2.7. Data Analysis. The $\mathrm{Pb}(\mathrm{II})$ concentration data were further analyzed to determine the removal rate of $\mathrm{Pb}^{2+}$ ions by using the PA mixture, as follows:

$$
R_{t}=\frac{\left(C_{0}-C_{t}\right)}{C_{0}} \times 100 \%,
$$

where $R_{t}$ was the removal rate of $\mathrm{Pb}^{2+}$ at sampling time $t(\%)$, $C_{t}$ was the $\mathrm{Pb}^{2+}$ concentration in the effluent sample that collected at time $t(\mathrm{mg} / \mathrm{L})$, and $C_{0}$ was the $\mathrm{Pb}^{2+}$ concentration in the synthetic rainwater $(\mathrm{mg} / \mathrm{L})$.

\section{Results and Discussion}

3.1. AV Distributions. Figure 6 demonstrates the vertical AV distribution characteristics in terms of content, number, and volume in two PA specimens at AV contents of $16 \%$ and $20 \%$, respectively. As shown in the figure, both specimens appear to have similar overall vertical distributions of $\mathrm{AV}$ content, AV number, and AV volume when they are compacted at different AV contents. Specifically, for each PA specimen, a typical vertical distribution of AV content and
$\mathrm{AV}$ volume values is observed, meaning the middle part of the specimen has less voids and they occupy a smaller volume than the ends. In contrast, the AV number is relatively homogeneously distributed throughout the sample height. Similar observations were not only reported by Hassan et al. [11], Mahmud et al. [29], and Alvarez et al. [20], but also predicted by Chen et al. [37] using a DEM-predicted model. The u-shaped vertical AV distribution is a suggested result of the "confinement effect" during the compaction process [29]. Furthermore, similar distribution patterns of AV content and AV number in the vertical direction inside dense-graded asphalt specimens were observed by Xu et al. [38], Masad and Button [39], and Hassan et al. [11] using different types of Superpave gyratory compaction (SGC) specimens compacted under different numbers of gyrations. All these results indicate that the general vertical patterns of AV content and AV volume distributions inside asphalt mixtures do not vary obviously with asphalt mixture type, AV content, aggregate gradation, or compaction method.

Not surprisingly, the data in Figure 6 show both AV content and volume within the specimen at the AV content of $20 \%$ was, in general, higher than those in the specimen at the AV content of $16 \%$. AV numbers were found varying in range from 192 to 294 for the specimen of $16 \%$ AV content, and from 207 to 305 for the specimen of $20 \%$ AV content. In addition, significant differences in AV content, number, and volume, between two specimens compacted at the AV content of $16 \%$ and $20 \%$, were, respectively, detected in the $T$-test ( $p<0.05 ; t=0.005,0.037$, and -14.528$)$, thus indicating that $\mathrm{AV}$ content, AV number, and AV volume in PA specimen are affected by AV content; one of the important parameters for PA mixture design. Moreover, the AV distribution can reveal that, for PA mixture designed with larger AV content, the lack of fine aggregates and relatively homogenous vertical distribution of voids leads to a higher variation in void content and volume. This means that more voids with smaller size are likely to be formed in the middle when the PA mixture is designed with a higher AV content.

Correlation analyses were conducted among the three distributional parameters including $\mathrm{AV}$ content, $\mathrm{AV}$ 
TABle 3: Preparation of synthetic rainwater for this study.

\begin{tabular}{|c|c|c|c|}
\hline Target pollutant & Concentration in literature & Chemical reagent & Initial concentration \\
\hline $\mathrm{Pb}^{2+}$ & $0.02 \sim 0.53(\mathrm{mg} / \mathrm{L})$ & $\begin{array}{l}\text { (1) } \mathrm{Pb}\left(\mathrm{NO}_{3}\right)_{2}(1000 \mathrm{mg} / \mathrm{L}) \\
\text { (2) Distilled water }\end{array}$ & $0.50(\mathrm{mg} / \mathrm{L})$ \\
\hline
\end{tabular}

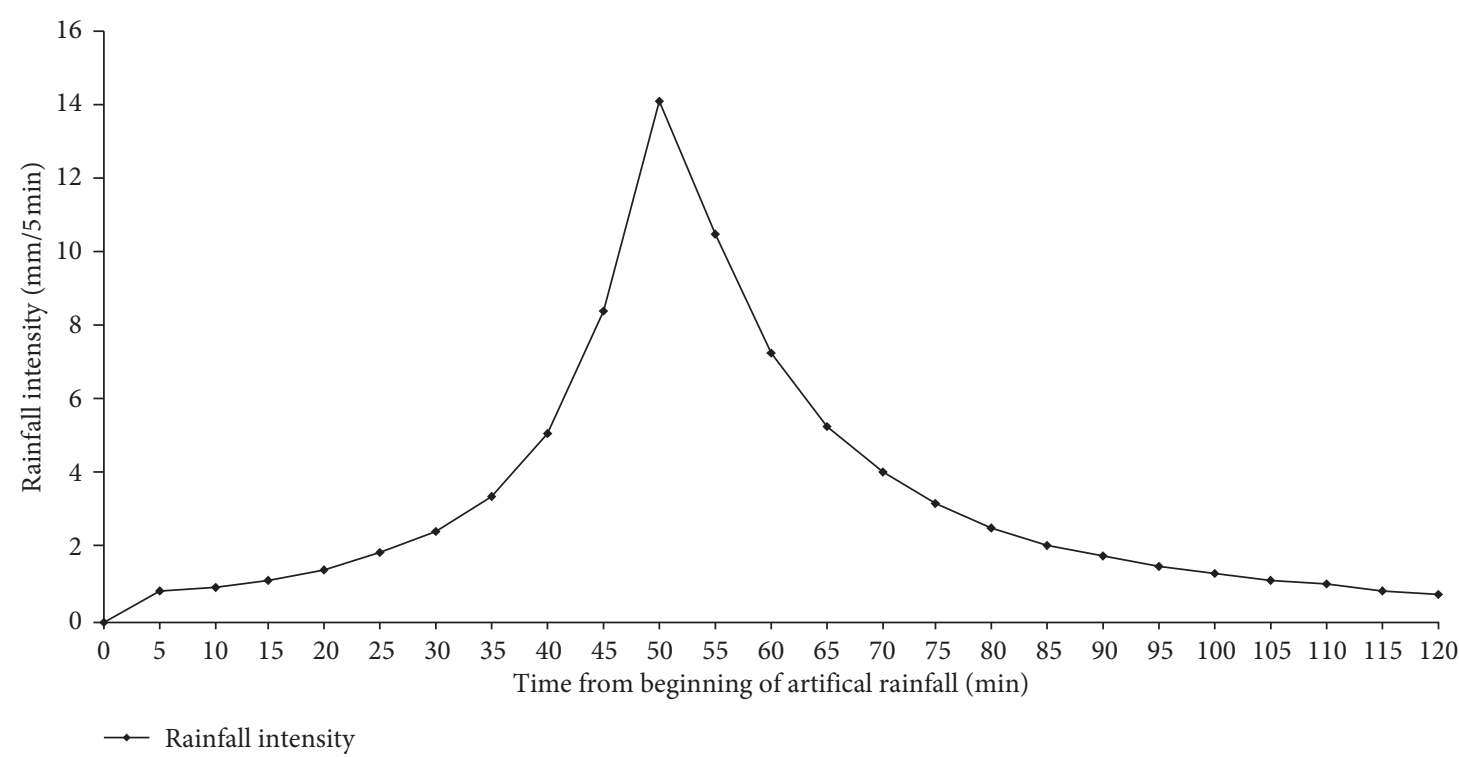

Figure 4: Rainfall storm designed according to the local conditions of Nanjing City (return period $=5$ years; $r=0.4 ;$ duration $=120$ minutes).

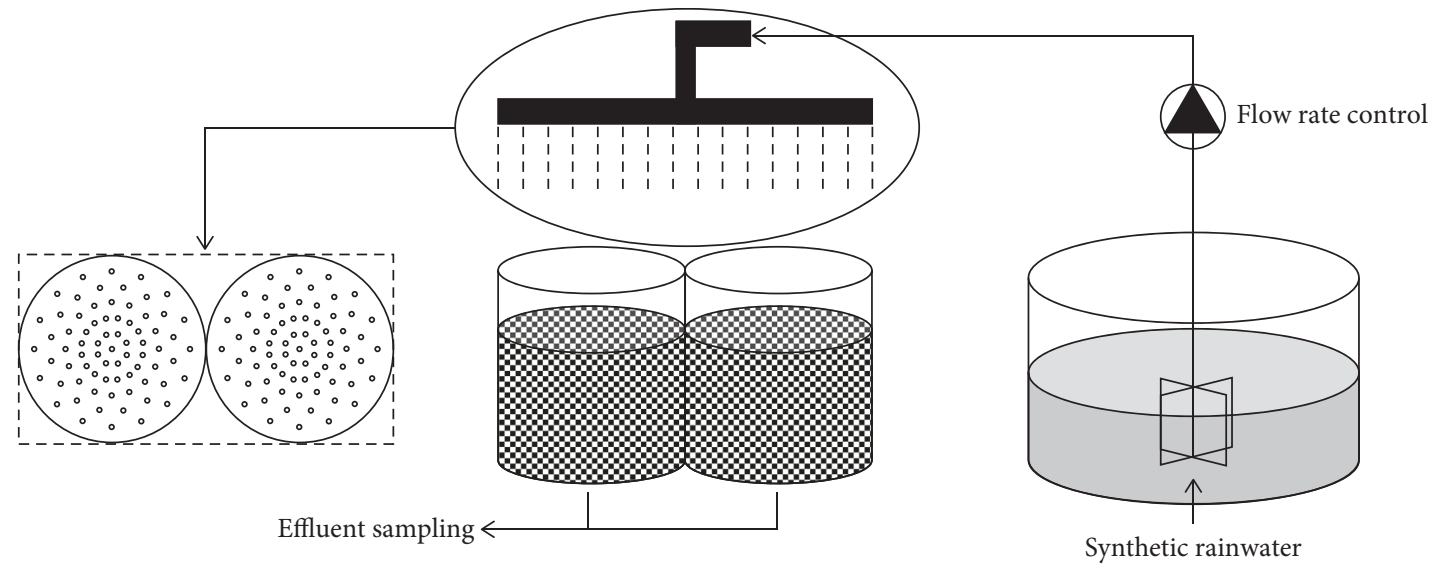

FIGURE 5: The scheme of the artificial rainfall experiment.

number, and AV volume for each PA specimen, and the results are shown in Table 4 . It can be seen that the correlation coefficients between AV content and AV number, $\mathrm{AV}$ content and $\mathrm{AV}$ volume, and $\mathrm{AV}$ number and $\mathrm{AV}$ volume are $-0.765,0.948$, and -0.747 for PAC-16(A); and $-0.690,0.819$, and -0.538 for PAC-16(B). The results demonstrate that significant interactions among these three parameters do exist. They reflect different aspects of void distribution in PA specimen and can have different influence on each other. Specifically, a remarkable positive correlation between AV volume and AV content exists; likewise, good negative correlations between AV content and AV number, and AV volume and AV number are here. The correlation coefficients for PAC-16(A) are obviously higher than PAC16(B), which imply that PA mixtures designed with a higher $\mathrm{AV}$ content can help form a good AV distribution.

3.2. AV Dimension. Figure 7 presents the distributions of $\mathrm{AV}$ dimensional properties including equivalent diameter, specific surface area, and fractal dimension through the specimen height, respectively. Similar to the overall distributions of AV content, number, and volume, obvious differences were not identified in the general vertical distributions of equivalent diameter, specific surface, and fractal dimension inside the specimens at two different $\mathrm{AV}$ 


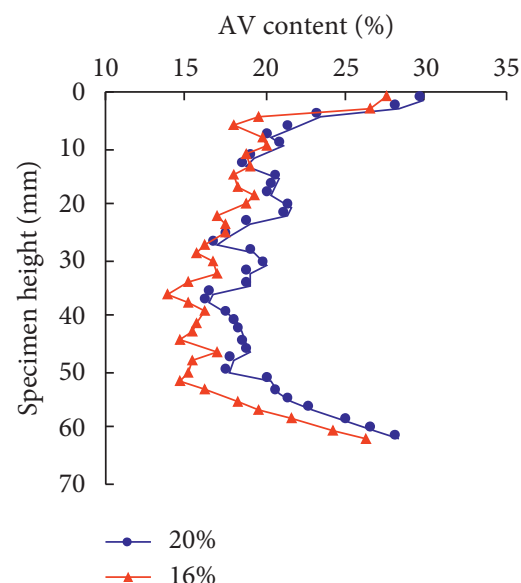

(a)

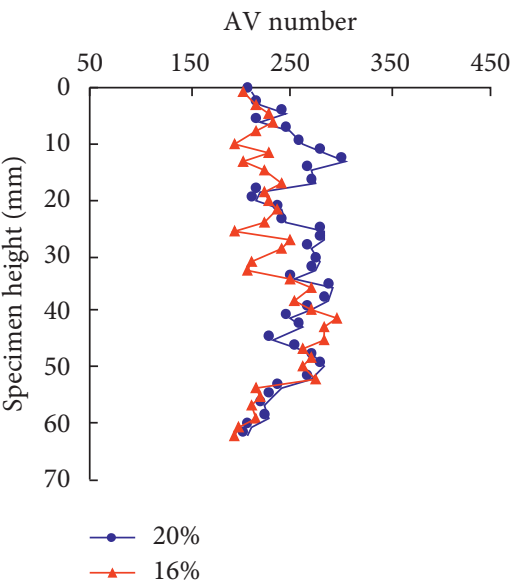

(b)

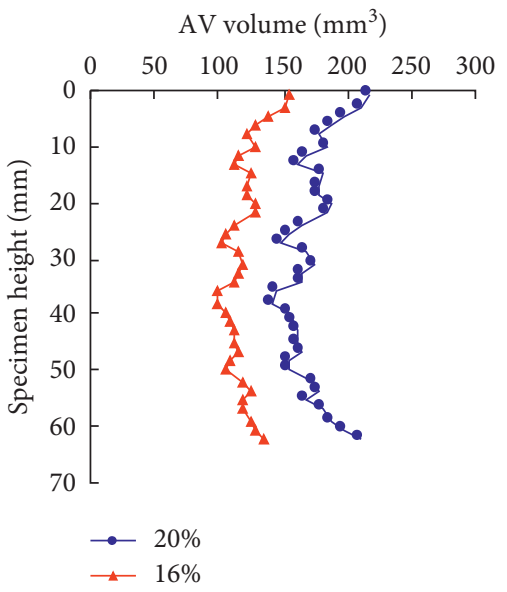

(c)

Figure 6: Vertical AV distribution in PA specimens at various AV contents of $16 \%$ and $20 \%$, respectively: (a) AV content, (b) AV number, and (c) AV volume.

TABLE 4: Correlations among the three distributional parameters.

\begin{tabular}{|c|c|c|c|c|c|c|}
\hline \multirow{3}{*}{ Parameter } & \multicolumn{6}{|c|}{ Correlation coefficient } \\
\hline & & PAC-16(A) & & & PAC-16(B) & \\
\hline & AV content & AV number & AV volume & AV content & AV number & AV volume \\
\hline AV content & 1.000 & -0.765 & 0.948 & 1.000 & -0.690 & 0.819 \\
\hline AV number & -0.765 & 1.000 & -0.747 & -0.690 & 1.000 & -0.538 \\
\hline $\mathrm{AV}$ volume & 0.948 & -0.747 & 1.000 & 0.819 & -0.538 & 1.000 \\
\hline
\end{tabular}

contents. For both specimens, the equivalent diameter values are relatively high on both ends but low in the middle, meaning that the average diameter of voids in the middle section of the specimen is relatively smaller than that in both the top and bottom sections. Meanwhile, both the specific surface area and fractal dimension levels remain relatively comparable throughout the specimen height, indicating that the surface texture of voids throughout the specimen height remains relatively constant. A similar pattern of void diameter distribution in the vertical direction was also observed by Mahmud et al. [29]. However, the parameter they used was equivalent projection area, which is a bit different from the one used in this study. Still, these results provide evidence for supporting the change in AV content, number, and volume with the specimen height, mentioned earlier in this article.

On the other hand, significant differences were identified in equivalent diameter, specific surface area, and fractal dimension between the two specimens compacted at an AV content of $16 \%$ and $20 \%$, respectively, in the $T$-test $(p<0.05$; $t=-6.197,-16.432$, and -45.746$)$. It indicates that the shape and size of AV in specimen are affected by AV content, but the distribution patterns through the specimen height are not strongly related to it.

Table 5 presents the correlation coefficients among the three-dimensional parameters in terms of equivalent diameter, specific surface area, and fractal dimension for PA specimens at different AV content of $20 \%$ and $16 \%$, respectively. For each specimen, significant negative relations between the equivalent diameter and specific surface area and the equivalent diameter and fractal dimension were identified. Meanwhile, a significant positive relation between the specific surface area and fractal dimension was found. These results suggest that fractal dimension increases with larger specific surface area and decreases with smaller equivalent diameter. Thus, this indicates that the voids with smaller diameter in PA specimen might have larger specific surface area and more complex geometries.

\subsection{Correlation between Distributional and Dimensional} Parameters. Table 6 presents the results of correlation analyses conducted between distributional and dimensional parameters for each specimen. For PAC-16(A) and PAC16(B) specimens, the calculated correlation coefficients between the equivalent diameter and three distributional parameters including $\mathrm{AV}$ content, $\mathrm{AV}$ number, and $\mathrm{AV}$ volume are in the range of $-0.933 \sim 0.935$ and $-0.891 \sim 0.860$, respectively, and are significant, which indicates good correlations between these examined variables. This result suggests that the correlations of specimen compacted at higher AV content seems better. According to equation (2), the equivalent diameter of $\mathrm{AV}$ is associated with the number and volume of $\mathrm{AV}$ in each image, regardless of AV content. But as shown in Figures 6 and 7, even though the distribution of AV content and number was almost similar, the AV volume formed differently within two specimens. Thus, the different coefficients of the two specimens as regard the 


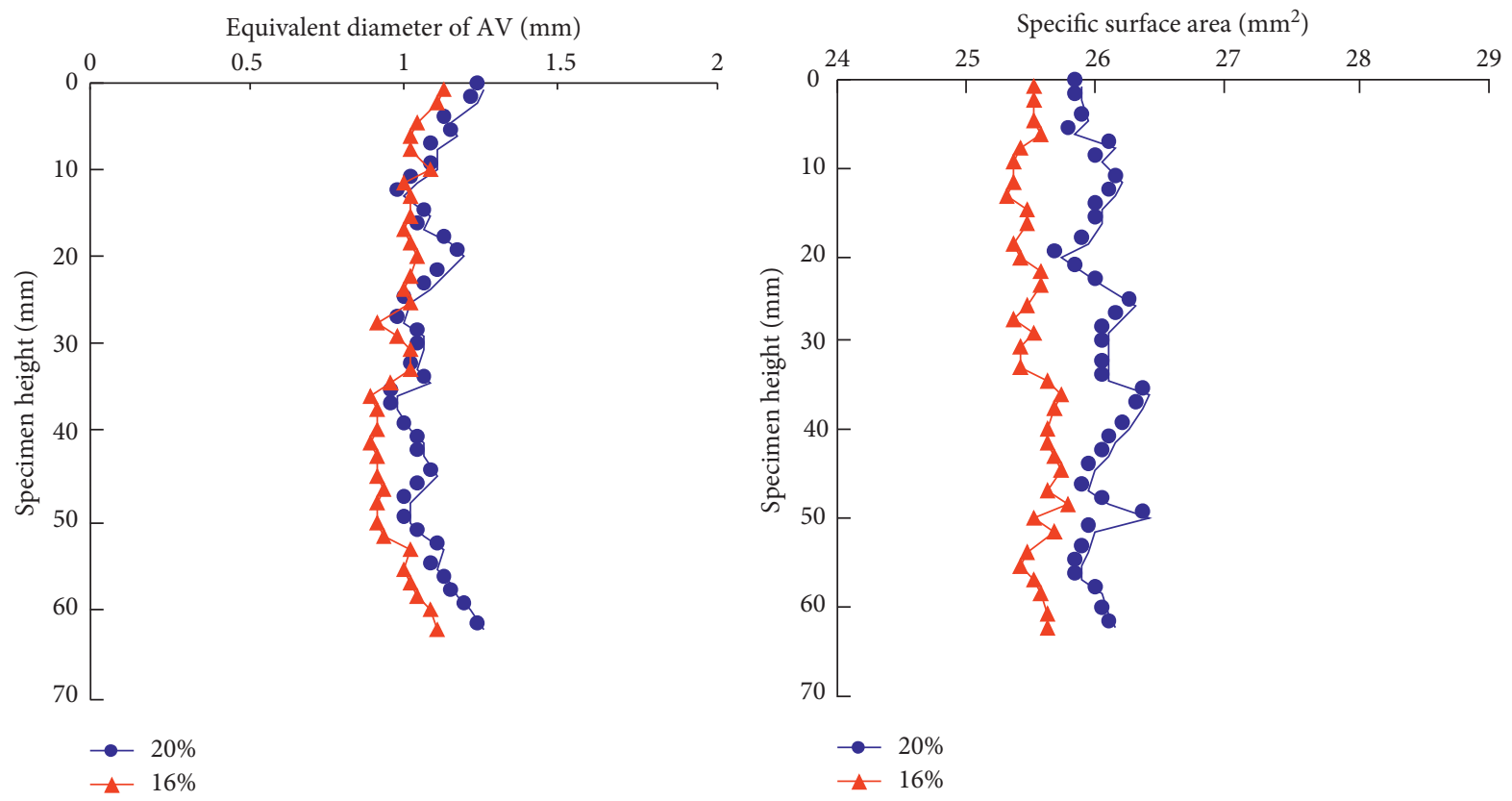

(a)

(b)

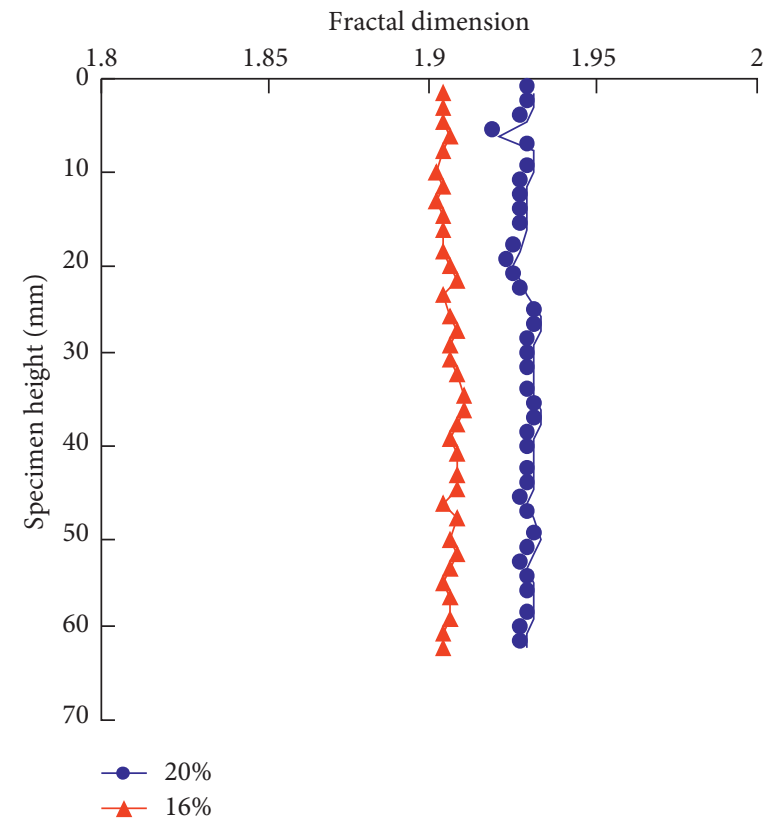

(c)

Figure 7: Vertical AV dimension in PA specimens with AV contents of $16 \%$ and $20 \%$, respectively: (a) equivalent diameter, (b) specific surface area, and (c) fractal dimension.

TABLE 5: Correlations among the three-dimensional parameters.

\begin{tabular}{|c|c|c|c|c|c|c|}
\hline \multirow[b]{3}{*}{ Parameter } & \multicolumn{6}{|c|}{ Correlation coefficient } \\
\hline & \multicolumn{3}{|c|}{ PAC-16(A) } & \multicolumn{3}{|c|}{ PAC-16(B) } \\
\hline & $\begin{array}{c}\text { Equivalent } \\
\text { diameter }\end{array}$ & $\begin{array}{c}\text { Specific } \\
\text { surface } \\
\text { area }\end{array}$ & $\begin{array}{c}\text { Fractal } \\
\text { dimension }\end{array}$ & $\begin{array}{c}\text { Equivalent } \\
\text { diameter }\end{array}$ & $\begin{array}{c}\text { Specific } \\
\text { surface } \\
\text { area }\end{array}$ & $\begin{array}{c}\text { Fractal } \\
\text { dimension }\end{array}$ \\
\hline $\begin{array}{l}\text { Equivalent } \\
\text { diameter }\end{array}$ & 1.000 & -0.702 & -0.501 & 1.000 & -0.452 & -0.628 \\
\hline Specific surface area & -0.702 & 1.000 & 0.691 & -0.452 & 1.000 & 0.567 \\
\hline Fractal dimension & -0.501 & 0.691 & 1.000 & -0.628 & 0.567 & 1.000 \\
\hline
\end{tabular}


TABLE 6: Correlations between distributional and dimensional parameters for characterizing AV in PAC-16(A) and PAC-16(B) specimens.

\begin{tabular}{|c|c|c|c|c|c|c|}
\hline \multirow[b]{3}{*}{ Parameter } & \multicolumn{6}{|c|}{ Correlation coefficient } \\
\hline & \multicolumn{3}{|c|}{ PAC-16(A) } & \multicolumn{3}{|c|}{ PAC-16(B) } \\
\hline & $\begin{array}{l}\text { Equivalent } \\
\text { diameter }\end{array}$ & $\begin{array}{c}\text { Specific } \\
\text { surface } \\
\text { area }\end{array}$ & $\begin{array}{c}\text { Fractal } \\
\text { dimension }\end{array}$ & $\begin{array}{c}\text { Equivalent } \\
\text { diameter }\end{array}$ & $\begin{array}{c}\text { Specific } \\
\text { surface } \\
\text { area }\end{array}$ & $\begin{array}{c}\text { Fractal } \\
\text { dimension }\end{array}$ \\
\hline $\mathrm{AV}$ content & 0.922 & -0.571 & -0.280 & 0.863 & -0.211 & -0.620 \\
\hline AV number & -0.933 & 0.691 & 0.469 & -0.891 & 0.618 & 0.602 \\
\hline $\mathrm{AV}$ volume & 0.935 & 0.469 & -0.463 & 0.860 & -0.174 & -0.493 \\
\hline
\end{tabular}

equivalent diameter were possibly mainly due to the difference in the distribution of AV volume.

Furthermore, relatively weak relations between fractal dimension and the three distributional parameters were found, demonstrating that fractal dimension is not strongly related to the AV distribution in the PA specimen. In addition, the specific surface area appears to depend on AV number because a significant positive correlation between specific surface area and AV number was found for each specimen. The finding of a relation between AV volume and fractal dimension in this study is consistent with the study by Alber et al. [33], where PA specimens had larger AV contents. These results provide evidence that both the dimensional and distributional parameters used in this study can describe the characteristics of AV formatted within the PA mixture. Moreover the AV characteristics are affected by the mutual influence between distribution pattern and dimensional of voids, regardless of the difference in $\mathrm{AV}$ contents.

3.4. $\mathrm{Pb}$ (II) Removal Performance of $\mathrm{PA}$ Specimen. Figure 8 shows the removal rate of tested heavy metal for PAC-16(A) and $\mathrm{PAC}-16(\mathrm{~B})$. The $\mathrm{Pb}(\mathrm{II})$ concentrations in the initial effluent discharging from PAC-16(A) and PAC-16(B) specimens were $0.3540 \mathrm{mg} / \mathrm{L}$ and $0.3512 \mathrm{mg} / \mathrm{L}$, respectively. It is not surprising that the $\mathrm{Pb}$ (II) concentration is approximately $30 \%$ lower in the initial effluent compared with the synthetic rainwater $(0.5 \mathrm{mg} / \mathrm{L})$, after 5 minutes from the beginning of the artificial rainfall event. Similar observation was reported in the previous research [18]. This result indicates that $\mathrm{PA}$ specimen can retain $\mathrm{Pb}(\mathrm{II})$ from initial runoff. This may be attributed to the microstructure of PA specimen. The image analyses in this study indicate that PA specimen has a significant amount of open voids with relatively high surface area. Metal ions from infiltrated runoff can be immobilized by both physical and chemical adsorptions. But the physical reactions are most likely to occur in such a short time.

Moreover, during the 120-minute rainfall event, the average removal rates were $33.19 \%$ and $32.76 \%$ for PAC16(A) and PAC-16(B), respectively, and no obvious difference was noticed. Also, the removal rate of $\mathrm{Pb}$ (II) appears not to change obviously with longer precipitation time and greater cumulative rainfall, because only approximately $5 \%$ difference was found in $\mathrm{Pb}(\mathrm{II})$ removal over the experimental period, for each PA specimen. These results means that $\mathrm{PA}$ mixture has the ability to trap dissolved $\mathrm{Pb}$ in stormwater and can remain relatively stable throughout the experiment. It is also implied that the removal of $\mathrm{Pb}$ (II) is possibly related to the penetration process of stormwater in PA mixture. $\mathrm{Pb}(\mathrm{II})$ in stormwater can be trapped in voids and adsorbed on the void surface. Previous study [40] has explored the behavior of using asphalt binder as a sorbent for heavy metals in stormwater indicate this to the case.

In addition, no significant difference was found in $\mathrm{Pb}$ (II) removal rates between $\mathrm{PA}$ specimens with different $\mathrm{AV}$ content of $16 \%$ and $20 \%$ in the $T$-test $(p>0.05)$. This result indicates that the $\mathrm{Pb}(\mathrm{II})$ removal capability of $\mathrm{PA}$ mixtures appears not to depend on the AV content. This is probably due to the very small difference in AV contents $(20 \%$ and $16 \%)$ for PAC-16(A) and PAC-16(B) used in this study.

3.5. Relationship between $\mathrm{Pb}(\mathrm{II})$ Removal and AV Characteristics in PA Specimen. Although significant differences were identified in AV characteristics between the two PA specimens compacted with different AV contents, no obvious difference was found in the removal rate of $\mathrm{Pb}$ (II) by using the same PA specimens and undergoing the same artificial rainfall event, as mentioned earlier. To further investigate the influence of AV properties and distribution in $\mathrm{PA}$ specimen on $\mathrm{Pb}(\mathrm{II})$ removal, correlation analyses were conducted between $\mathrm{Pb}(\mathrm{II})$ removal rates and all parameters for characterizing $\mathrm{AV}$ dimension and distribution including AV content, AV number, AV volume, equivalent diameter, specific surface area, and fractal dimension for each PA specimen, respectively, and the results are shown in Table 7.

It can be seen from Table 7 the calculated correlation coefficients are in a wide range from -0.731 to 0.439 , and some are not significant. But significant negative correlations were calculated between equivalent diameter and $\mathrm{Pb}$ (II) removal, $\mathrm{AV}$ content and $\mathrm{Pb}$ (II) removal, and $\mathrm{AV}$ number and $\mathrm{Pb}$ (II) removal rate for each specimen. This means that the removal rate of $\mathrm{Pb}$ (II) is correlated with these three parameters. Specifically, the correlation coefficients are $-0.560,-0.731$, and -0.582 for PAC-16(A), and -0.498 , -0.697 , and -0.606 for PAC-16(B). By contrast, relatively weak correlation between $\mathrm{Pb}(\mathrm{II})$ removal and $\mathrm{AV}$ number was identified for each specimen. Furthermore, the calculated correlation coefficient between $\mathrm{Pb}(\mathrm{II})$ removal and fractal dimension are 0.018 for PAC-16(A), and 0.237 for PAC-16(B), while the correlation coefficient between $\mathrm{Pb}$ (II) removal and specific surface area are 0.299 for PAC-16(A), and -0.080 for PAC-16(B), respectively, demonstrating that 


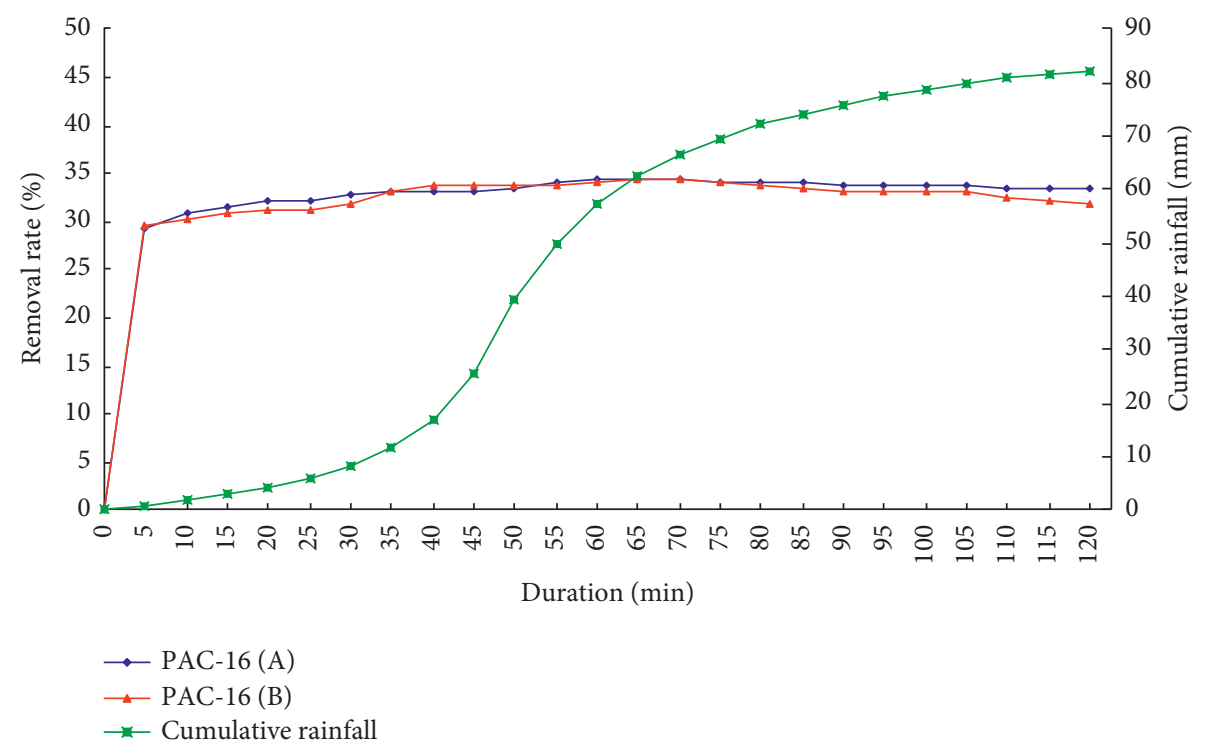

Figure 8: The removal rate of $\mathrm{Pb}(\mathrm{II})$ for $\mathrm{PA}$ specimens with different $\mathrm{AV}$ contents.

TABle 7: Correlations between removal rate of $\mathrm{Pb}(\mathrm{II})$ and parameters for characterizing voids in both.

\begin{tabular}{lcccccc}
\hline \multirow{2}{*}{ Removal rate } & & & & Correlation coefficient \\
& AV content & AV number & AV volume & Equivalent diameter & Specific surface area & Fractal dimension \\
\hline $\mathrm{Pb}(\mathrm{II})(\mathrm{A})$ & -0.731 & 0.439 & -0.582 & -0.560 & 0.299 & 0.018 \\
$\mathrm{~Pb}(\mathrm{II})$ (B) & -0.697 & 0.229 & -0.606 & -0.498 & -0.080 & 0.237 \\
\hline
\end{tabular}

Note. A and B in parentheses represent PAC-16(A) and PAC-16(B) specimens, respectively.

weak to no correlation existed between the examined variables. All these results suggest that the removal of $\mathrm{Pb}$ (II) over the study period is more strongly affected by the vertical AV distribution inside the PA mixture compared with the $\mathrm{AV}$ dimensional properties, regardless of the AV content. The $\mathrm{Pb}(\mathrm{II})$ removal of a certain $\mathrm{PA}$ mixture increases with smaller AV content, AV volume, and equivalent diameter while reduces with a smaller AV number. Thus, besides a reasonable mixture design, a u-shaped vertical AV distribution formed inside PA mixtures is appropriate for getting a high $\mathrm{Pb}(\mathrm{II})$ removal rate.

Based on the correlation coefficients listed in Table 7, the $\mathrm{Pb}$ (II) removal capability of $\mathrm{PA}$ mixture seems to not be directly related to the dimensional properties of voids compared to the AV distribution throughout the sample height, but the dimensional parameters show weak to good correlation with distributional parameters (as shown in Table 6). Thus, the rough and complex surface of the voids inside the PA mixture proved more or less beneficial to the removal of $\mathrm{Pb}(\mathrm{II})$. In this sense, it is consistent with the research result that porous material with higher specific surface area is beneficial for higher metal adsorption capacity and faster kinetics [41]. However, the removal of $\mathrm{Pb}(\mathrm{II})$ in this study is possibly limited by the relatively short period of contact time between the infiltrated stormwater and PA mixture material; thus, some of the chemical reactions aiding heavy metal adsorption cannot occur during such short contact time. As a result, the $\mathrm{Pb}$ (II) removal capability of PA mixtures appears to not be directly enhanced by the complex geometries of voids when compared to the vertical distribution of $\mathrm{AV}$.

Noting that the PA mixture does not provide a temporary storage for infiltrated stormwater in this study, these results reveal that the vertical AV distribution in PA mixture is an important factor affecting the system's $\mathrm{Pb}$ (II) removal capability. Since the void spaces in PA mixtures are the only pathways for stormwater transportation, the experimental results also reflect that the voids of greater specific surface area and more complex geometries do lead to a higher $\mathrm{Pb}$ (II) removal performance of PA pavements by providing a temporary storage for infiltrated stormwater. In this regard, the removal of $\mathrm{Pb}$ (II) from stormwater using a $\mathrm{PA}$ mixture during a rainfall event can be greatly enhanced by controlling the compaction process and mixture design to develop a perfect $A V$ distribution that contains many small voids towards the top and bottom of the mixture sections.

\section{Conclusions}

In this study, a type of PA mixture, PAC-16, was designed at two different AV contents (16\% and 20\%). The AV properties and distribution inside PA mixtures were identified using the X-ray CT and related digital image analysis technologies, with both dimensional and distributional parameters. The removal performance of $\mathrm{Pb}$ (II) from stormwater with PA mixtures was then investigated by 
creating an artificial rainfall event. The relation between the $\mathrm{AV}$ characteristics and $\mathrm{Pb}(\mathrm{II})$ removal capability of $\mathrm{PA}$ mixture in particular were determined. The main findings are as follows:

(1) The mixture design parameter, AV content, does not appear to affect the overall vertical distribution of AV in the PA mixture but the distributional and dimensional parameters are affected. Even though the AV contents are different, the microstructure properties of PA are comparable for both type of gradations used.

(2) In general, the AV content, AV volume, and equivalent diameter are higher towards the top and bottom of the specimen but lower in the middle part, whereas the AV number, specific surface area, and fractal dimension are relatively homogeneously distributed throughout the sample height.

(3) Regarding the correlations among the examined variables, the distributional parameters including $\mathrm{AV}$ content, AV number, and AV volume show good to perfect correlations with each other and so do the three-dimensional parameters including equivalent diameter, specific surface area, and fractal dimension. Overall, good correlation is found between distributional and dimensional parameters.

(4) Both PA mixtures performed acceptably from the $\mathrm{Pb}$ (II) removal perspective because the $\mathrm{Pb}(\mathrm{II})$ removal rates were approximately $33 \%$ or higher over the 120 minutes of rainfall event without providing a temporary storage of stormwater in PA mixture. However, the higher AV content is not demonstrated to be an effective way to improve the $\mathrm{Pb}$ (II) removal capability.

(5) The $\mathrm{Pb}(\mathrm{II})$ removal rate shows good correlations with AV content, AV volume, AV number, and equivalent diameter, but poor correlations with specific surface area and fractal dimension. This result indicates that the $\mathrm{Pb}(\mathrm{II})$ removal capability of a PA mixture that does not provide a temporary storage for infiltrated stormwater over the rainfall period is more directly related to the distribution pattern of $\mathrm{AV}$ than detailed characteristics of $\mathrm{AV}$.

\section{Data Availability}

Some proceeded data of X-ray CT images and removal rate data that reported previously were used to support the finding of this study and are available at DOI: 10.3969/ j.issn.1674-0696.2018.05.08. This prior study is cited at relevant places within the text as reference [36].

\section{Conflicts of Interest}

The authors declare that there are no conflicts of interest regarding the publication of this paper.

\section{Acknowledgments}

This research was funded by the Natural Science Foundation of the Jiangsu Higher Education Institutions of China (grant number 17KJB580007); the Basic Research Program (Natural Science Foundation) of Jiangsu Province, China (grant number BK20170933); the Science and Technology Plan Program of Ministry of Housing and Urban-Rural Development of the People's Republic of China (grant number 2018-K9-074); and the Priority Academic Program Development of Jiangsu Higher Education Institutions (PAPD). The authors would like to thank the Civil Engineering Experimental Center of Nanjing Forestry University and Tongji University for all the support provided to them. Additionally, the writers thank Liam Sprangers from the University of Victoria for grammar check and correction.

\section{References}

[1] M. Scholz and P. Grabowiecki, "Review of permeable pavement systems," Building and Environment, vol. 42, no. 11, pp. 3830-3836, 2007.

[2] J. Huang, C. Valeo, J. He, and A. Chu, "Three types of permeable pavements in cold climates: hydraulic and environmental performance," Journal of Environmental Engineering, vol. 142, no. 6, article 04016025, 2016.

[3] B. K. Ferguson, Porous Pavements, Taylor \& Francis, Boca Raton, FL, USA, 2012.

[4] M. Legret, V. Colandini, and C. Le Marc, "Effects of a porous pavement with reservoir structure on the quality of runoff water and soil," Science of the Total Environment, vol. 189-190, pp. 335-340, 1996.

[5] Y. Zhao, S. Zhou, C. Zhao, and C. Valeo, "The influence of geotextile type and position in a porous asphalt pavement system on $\mathrm{Pb}$ (II) removal from stormwater," Water, vol. 10, no. 9, p. 1025, 2018.

[6] Z. Zhang, Z. Li, X. Zhang, Z. Li, and H. Li, "Systematically investigated the influence of permeable pavement materials on the water quality of runoff: batch and column experiments," Water, Air, and Soil Pollution, vol. 229, no. 5, p. 155, 2018.

[7] V. Ranieri, M. C. Antonacci, G. Ying, and J. J. Sansalone, "Application of Kozeny-Kovàcs model to predict the hydraulic conductivity of permeable pavements," Transportation Research Record: Journal of the Transportation Research Board, vol. 2195, no. 1, pp. 168-176, 2010.

[8] T. M. Vadas, M. Smith, and H. Luan, "Leaching and retention of dissolved metals in particulate loaded pervious concrete columns," Journal of Environmental Management, vol. 190, no. 4, pp. 1-8, 2017.

[9] M. E. Dietz, "Low impact development practices: a review of current research and recommendations for future directions," Water, Air, and Soil Pollution, vol. 186, no. 1-4, pp. 351-363, 2007.

[10] A. E. Alvarez, A. E. Martin, and C. Estakhri, "Connected air voids content in permeable friction course mixtures," Journal of Testing and Evaluation, vol. 37, no. 3, pp. 254-263, 2009.

[11] N. A. Hassan, M. Z. H. Mahmud, K. A. Ahmad, M. R. Hainin, R. P. Jaya, and N. Mashros, "Air voids characterization and permeability of porous asphalt gradations used in different countries," Journal of Engineering and Applied Sciences, vol. 11, no. 24, pp. 14043-14047, 2016. 
[12] M. L. Afonso, M. Dinis-Almeida, and C. S. Fael, "Study of the porous asphalt performance with cellulosic fibres," Construction and Building Materials, vol. 135, pp. 104-111, 2017.

[13] G. Stotz and K. Krauth, "The pollution of effluents from pervious pavements of an experimental highway section: first results," Science of the Total Environment, vol. 146-147, pp. 465-470, 1994.

[14] B. J. Eck, R. J. Winston, W. F. Hunt, and M. E. Barrett, "Water quality of drainage from permeable friction course," Journal of Environmental Engineering, vol. 138, no. 2, pp. 174-181, 2012.

[15] J. Chen, H. Wang, and H. Zhu, "Investigation of permeability of open graded asphalt mixture considering effects of anisotropy and two-dimensional flow," Construction and Building Materials, vol. 145, pp. 318-325, 2017.

[16] R. M. Roseen, T. P. Ballestero, K. M. Houle, and D. Heath, "Assessment of winter maintenance of porous asphalt and its function for chloride source control," Journal of Transportation Engineering, vol. 140, no. 2, article 04013007, 2014.

[17] A. M. Al-Rubaei, A. L. Stenglein, M. Viklander, and G.-T. Blecken, "Long-term hydraulic performance of porous asphalt pavements in Northern Sweden," Journal of Irrigation and Drainage Engineering, vol. 139, no. 6, pp. 499-505, 2013.

[18] Y. Zhao and C. Zhao, "Lead and zinc removal with storage period in porous asphalt pavement," Water $S A$, vol. 40 , no. 1 , pp. 65-72, 2014.

[19] L. D. Poulikakos and M. N. Partl, "Investigation of porous asphalt microstructure using optical and electron microscopy," Journal of Microscopy, vol. 240, no. 2, pp. 145-154, 2010.

[20] A. E. Alvarez, A. E. Martin, and C. Estakhri, "Internal structure of compacted permeable friction course mixtures," Construction and Building Materials, vol. 24, no. 6, pp. 1027-1035, 2010.

[21] A. E. Alvarez-Lugo, O. J. Reyes-Ortiz, and R. Miró, "A review of the characterization and evaluation of permeable friction course mixtures," Ingeniare. Revista chilena de ingeniería, vol. 22, no. 4, pp. 469-482, 2014.

[22] V. Ranieri, G. Ying, and J. Sansalone, "Drainage modeling of roadway systems with porous friction courses," Journal of Transportation Engineering, vol. 138, no. 4, pp. 395-405, 2012.

[23] B. Huang, L. N. Mohammad, A. Raghavendra, and C. Abadie, "Fundamentals of permeability in asphalt mixtures," Journal of the Association of Asphalt Paving Technologists, vol. 68, pp. 479-500, 1999.

[24] K. Kanitpong, C. H. Benson, and H. U. Bahia, "Hydraulic conductivity (permeability) of laboratory-compacted asphalt mixtures," Transportation Research Record: Journal of the Transportation Research Board, vol. 1767, no. 1, pp. 25-32, 2001.

[25] A. Benedetto, "Open graded asphalt mixes: permeability and mechanical characteristics," International Journal of Pavement, vol. 6, no. 1, pp. 63-74, 2007.

[26] V. Ranieri, P. Colonna, J. J. Sansalone, and A. Sciddurlo, "Measurement of hydraulic conductivity in porous mixes," Transportation Research Record: Journal of the Transportation Research Board, vol. 2295, no. 1, pp. 1-10, 2012.

[27] V. Ranieri, P. Colonna, G. Ying, and J. Sansalone, "Model of flow regimes in porous pavement and porous friction courses," Transportation Research Record: Journal of the Transportation Research Board, vol. 2436, no. 1, pp. 156-166, 2014.

[28] A. E. Alvarez, J. C. Mora, and L. V. Espinosa, "Quantification of stone-on-stone contact in permeable friction course mixtures based on image analysis," Construction and Building Materials, vol. 165, pp. 462-471, 2018.
[29] M. Z. H. Mahmud, N. A. Hassan, M. R. Hainin, and C. R. Ismail, "Microstructural investigation on air void properties of porous asphalt using virtual cut section," Construction and Building Materials, vol. 155, pp. 485-494, 2017.

[30] Ministry of Housing and Urban-Rural Development of the People's Republic of China, Technique Specification for Permeable Asphalt Pavement (CJJ/T 190-2012), China Architecture and Building Press, Beijing, China, 2012.

[31] Ministry of Transport of the People's Republic of China, Technical Specification for Construction of Highway Asphalt Pavement (JTG F40-2004), China Communications Press, Beijing, China, 2004.

[32] Ministry of Transport of the People's Republic of China, Standard Test Methods of Bitumen and Bituminous Mixtures for Highway Engineering (JTG E20-2011), China Communications Press, Beijing, China, 2011.

[33] S. Alber, W. Ressel, P. Liu et al., "Investigation of microstructure characteristics of porous asphalt with relevance to acoustic pavement performance," International Journal of Transportation Science and Technology, vol. 7, no. 3, pp. 199-207, 2018.

[34] Y. Hou, Y. Huang, F. Sun, and M. Guo, "Fractal analysis on asphalt mixture using a two-dimensional imaging technique," Advances in Materials Science and Engineering, vol. 2016, Article ID 8931295, 7 pages, 2016.

[35] T. Liu, X.-n. Zhang, Z. Li, and Z.-q. Chen, "Research on the homogeneity of asphalt pavement quality using X-ray computed tomography (CT) and fractal theory," Construction and Building Materials, vol. 68, pp. 587-598, 2014.

[36] Y. Zhao, L. Tong, Y. Zhu, and Y. Wei, "Influence mechanism of microscopic void characteristics on $\mathrm{Pb}^{2+}$ removal from road runoff in porous asphalt surface layer," Journal of Chongqing Jiaotong University (Natural Science), vol. 37, no. 5, pp. 41-46, 2018, in Chinese.

[37] J. Chen, B. Huang, and X. Shu, "Air-void distribution analysis of asphalt mixture using discrete element method," Journal of Materials in Civil Engineering, vol. 25, no. 10, pp. 1375-1385, 2013.

[38] H. Xu, F. Chen, X. Yao, and Y. Tan, "Micro-scale moisture distribution and hydrologically active pores in partially saturated asphalt mixtures by X-ray computed tomography," Construction and Building Materials, vol. 160, pp. 653-667, 2018.

[39] E. Masad and J. Button, "Implications of experimental measurements and analyses of the internal structure of hotmixed asphalt," Transportation Research Record: Journal of the Transportation Research Board, vol. 1891, no. 1, pp. 212-220, 2014.

[40] Y. Zhao, C. Zhao, K. Hill, and X. Q. Xu, "Laboratory-based investigation into the removal behaviour of asphalt in porous asphalt mixture on zinc ions from road runoff," Chiang Mai Journal of Science, vol. 44, no. 4, pp. 1601-1610, 2017.

[41] X. Qu, P. J. J. Alvarez, and Q. Li, "Applications of nanotechnology in water and wastewater treatment," Water Research, vol. 47, no. 12, pp. 3931-3946, 2013. 


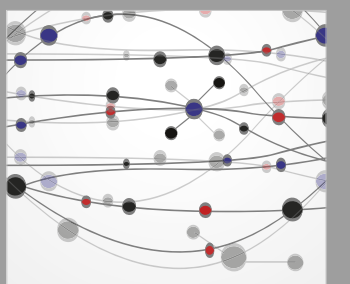

The Scientific World Journal
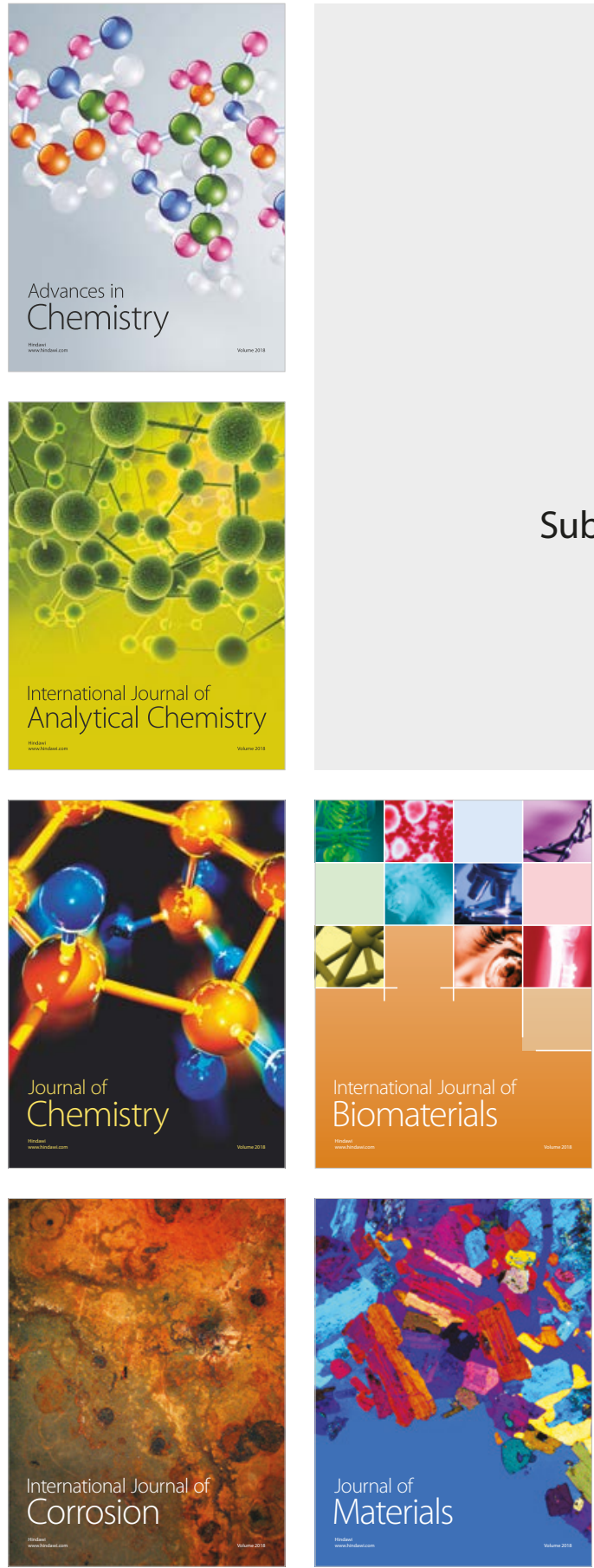

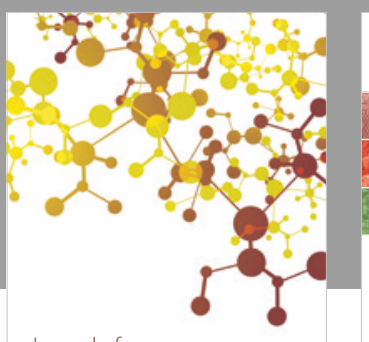

Journal of

Applied Chemistry
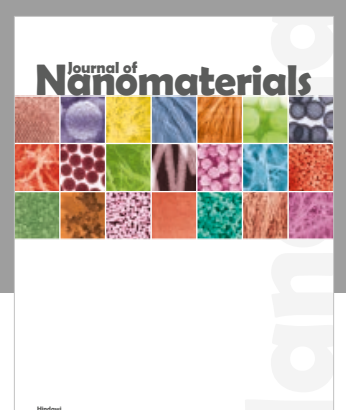

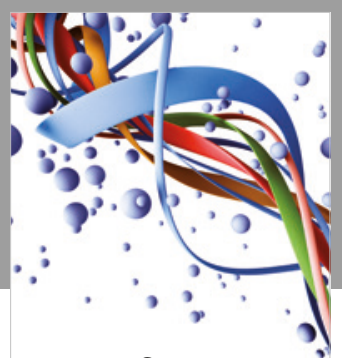

Scientifica

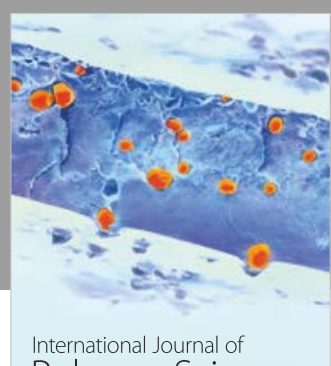

Polymer Science

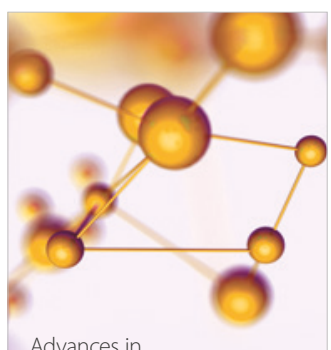

Physical Chemistry
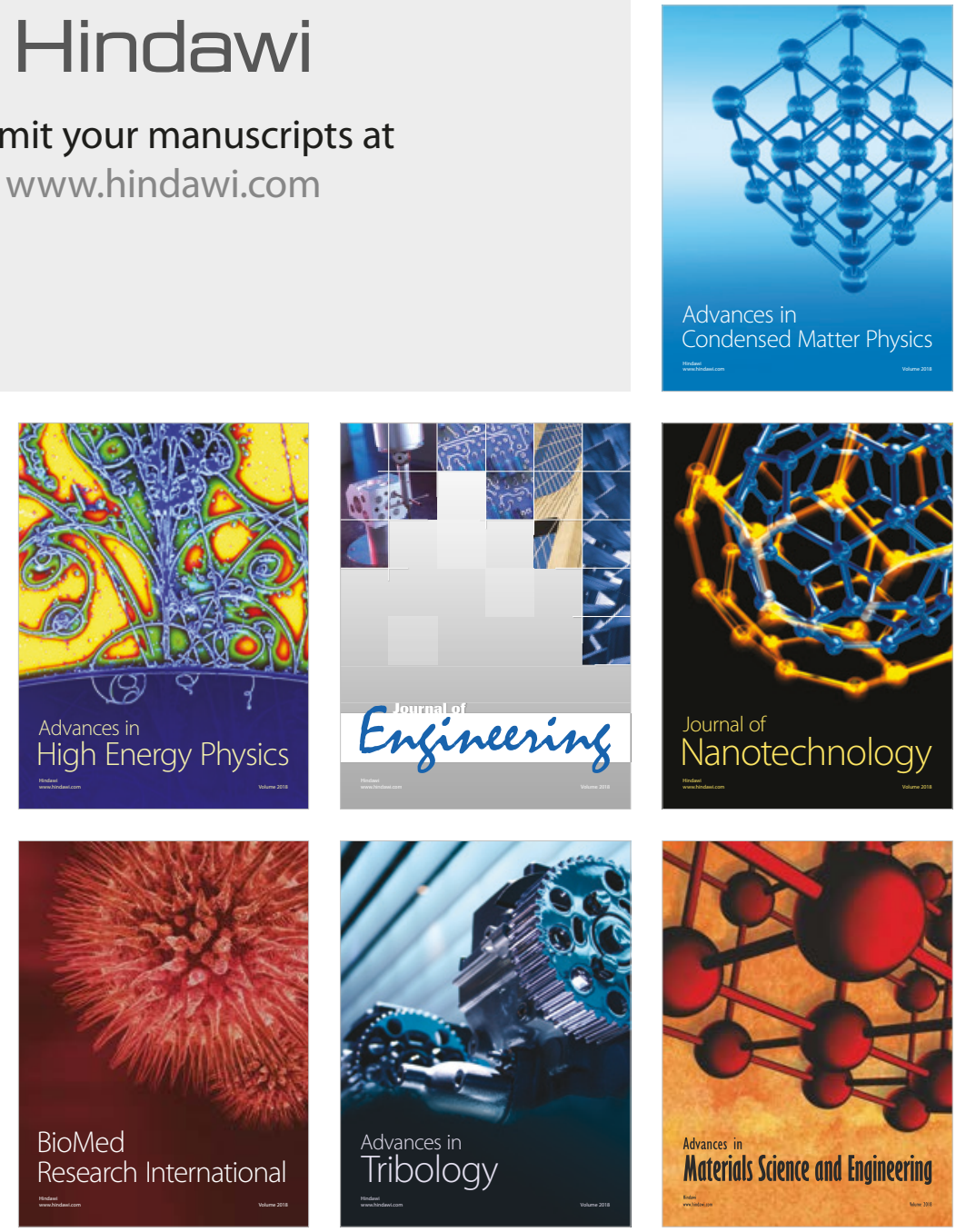